Original Research Paper

\title{
Natural Repellent Anthraquinone Applied on Cereal Grain Seeds and Seedlings Against Pigeons (Columba livia) in Captivity
}

\author{
${ }^{1}$ Kan Khoomsab and ${ }^{2}$ Itsara Tangsuwan \\ ${ }^{1}$ Education Science Program, Faculty of Science and Technology, \\ Phetchabun Rajabhat University, Phetchabun, Thailand \\ ${ }^{2}$ Environmental Science Program, Faculty of Science and Technology, \\ Phetchabun Rajabhat University, Phetchabun, Thailand
}

\section{Article history}

Received: 31-10-2019

Revised: 11-12-2019

Accepted: 12-12-2019

Corresponding Author:

Kan Khoomsab

Education Science Program,

Faculty of Science and

Technology, Phetchabun

Rajabhat University,

Phetchabun, Thailand 67000

Email: topkan13@hotmail.com

\begin{abstract}
This research aims to test the effects of cassia leaf extract on the eating behavior of pigeons for application as a natural repellent. Senna siamea (Cassia) leaves were oven-dried and blended into fine pieces and processed by the simplest extraction method (maceration) with ethyl alcohol $70 \%$ solution and were then extracted with hot continuous extraction (Soxhlet extraction) with ethyl alcohol $70 \%$ solution. Cereal grain seeds were prepared and soaked in the extracts of the 2 methods in $1.5 \%, 3.0 \%$ and $4.5 \%$ concentrations for $24 \mathrm{~h}$. Twenty-four pigeons were prepared with one cage per pigeon. Cereal grains were weighed to 20 grams, which was fed to the pigeons for $24 \mathrm{~h}$ and the beginning weight of the cereal grains and the weight of the leftovers were recorded. The food consumption was analyzed to determine the differences among the averages of each method with one-way ANOVA. The findings showed that the averages of the bird food intake based on the maceration method were not different with a statistical significance ( $p>0.05$ ), while the averages of the bird food intake based on Soxhlet extraction were different with a statistical significance $(\mathrm{p}<0.05)$. The bird food processed by the Soxhlet extraction method had a lower average consumption than that of the maceration method.
\end{abstract}

Keywords: Natural Repellents, Anthraquinone, Pigeon, Senna siamea

\section{Introduction}

Various kinds of birds cause problems that damage houses, communities, buildings and agricultural products; bird droppings are especially problematic because they cause damage to houses and buildings and become a public health problem as a source of the accumulation and distribution of diseases that have effects on human health (Avery, 1992; Avery et al., 1997; 1998). At present, bird control employs a physical method with the use of netting to prevent birds from nesting in and dirtying buildings. There are 4 major methods to repel birds: Physical prevention, sound bird deterrents, visual bird deterrents to scare birds away and the use of biochemicals (Bishop et al., 2003; Vantassel, 2010). To manage and control birds by repelling them from agricultural plots, including farm and garden plants, Integrated Pest Management (IPM) can be utilized. Many international research papers have indicated that coating or spraying plant extracts, such as anthraquinone, on plants or seeds can repel birds and prevent birds from eating those plants. Its activation will disturb the working system of a bird's gastrointestinal tract, thus causing the birds to excrete many droppings. This deterrent will enable birds to learn to avoid foods that have a bad effect on their health, thus encouraging them not to eat agricultural products in plots any longer (Umeda and Sullivan, 2001; Kandel et al., 2009; Linz and Homan, 2012; Werner et al., 2014).

The application of anthraquinone was mixed with plant seeds to study its efficiency as a bird repellent. Werner et al. (2009) established the repellency thresholds of an anthraquinone-based repellent for Canada geese Branta canadensis, red-winged blackbirds Agelaius phoeniceus and ring-necked pheasants (Phasianus colchicus) in captivity. Anthraquinone-based bird repellents can be used for the protection of agricultural crops, property and related natural resources. Esther et al. (2013) studied the effect of seed treatments with three substances that are likely to 
affect bird feeding behavior (anthraquinone, pulegone and methyl anthranilate were tested). The results show that anthraquinone, methyl anthranilate and pulegone had a repellent effect when used in the treatment of maize seeds in indoor feeding experiments. Ahmad et al. (2018) performed an experiment on mixing anthraquinone with corn seeds and feeding Eurasian tree sparrows. It was found that Eurasian tree sparrows ate food treated with anthraquinone had a lower consumption rate than did the control group, with a statistical significance. Khoomsab and Khoomsab (2019) tested $1 \%$ anthraquinone extracts from golden shower pods mixed in pigeon food compared to normal bird food and found that pigeons had a lower consumption rate of food treated with the extracts than did the control group, with a statistical significance. The test of anthraquinone usage as a repellent in sunflower seeds was conducted with red-winged blackbirds, common grackles and ring-necked pheasants .For red-winged blackbirds, anthraquinone was shown to have greater than $80 \%$ effectiveness of repellency for the seed that was treated with $1,994 \mathrm{mg}$ anthraquinone $\mathrm{kg}^{-1}$ in an experiment on the concentration and reactions (Werner et al., 2009). In New Zealand, a similar experiment was conducted with wheat and house sparrows (Passer domesticus L). In a comparison of $323-860 \mathrm{mg}$ anthraquinone $\mathrm{kg}^{-1}$ concentration treated wheat seeds and untreated wheat seeds, the treated seeds were consumed less often than were the untreated ones in each test (Clapperton et al., 2012; Day et al., 2012). In Pakistan, wheat seeds that were treated with higher concentrated anthraquinone ranging from 2,500-10,000 mg anthraquinone $\mathrm{kg}^{-1}$ were shown to have up to $80 \%$ effectiveness against house sparrows apart from untreated seeds (Ahmad et al., 2015).

In Thailand, anthraquinones have not been produced as bird repellents, based on the review of related literature and research papers. If anthraquinones are extracted from plants in Thailand for an experiment, the extracts will probably be used as bird repellents in agricultural plots of the country. Cassia (Senna siamea) is a plant that is reported to contain anthraquinone (Sakulpanich and Gritsanapan, 2009; Dave and Led, 2012; Bussmann et al., 2013; Shami, 2015). To create a body of knowledge related to bird management and control in Thailand, the researcher is interested in studying extracts from cassia leaves (Senna siamea), which act as potential agents against the eating behavior of pigeons and can be developed further as bird repellents in agricultural plots, since cassia leaf extracts are safe and eco-friendly, thus mitigating the problems caused by bird damage in agricultural products.

\section{Materials and Methods}

\section{Preparation of Plant Extraction}

Cassia leaves were collected from Maung District, Phetchabun Province. They were prepared by drying plant samples for 3 days at $60^{\circ} \mathrm{C}$. The samples were ground into powder and then stored in the desiccator for further analysis.

\section{Maceration}

Cassia powder weighing exactly $10 \mathrm{~g}$ was macerated with $100 \mathrm{~mL} \mathrm{70 \%} \mathrm{ethanol.} \mathrm{The} \mathrm{extraction}$ was repeated until exhausted. The maceration extracts were combined, filtered and evaporated to dryness by rotary evaporation; placed in a water bath; and, finally, treated with a lyophilizer to yield maceration crude extract.

\section{Soxhlet extraction}

Cassia leaves weighing exactly $10 \mathrm{~g}$ were extracted with $200 \mathrm{~mL} 70 \%$ ethanol in a Soxhlet apparatus using reflux 4 times until the extraction was exhausted. The extract was filtered with filter paper No. 1. The evaporating dish was dried in an oven. A rotary vacuum evaporator was used to remove solvent from the obtained extract. The weight and percentage of the obtained crude extract were calculated. The volume reached $100 \mathrm{~mL}$.

The extract was contained in an amber glass bottle and dried in a hot air oven at a temperature of $65^{\circ} \mathrm{C}$ to perform the experiment and calculate the extraction yield as the percentage (\% yield) from the following equation:

$$
\% \text { Yield }(\mathrm{w} / \mathrm{w})=\frac{\text { Weight of the crude extract }(\mathrm{g})}{\text { Weight of raw material }(\mathrm{g})} \times 100
$$

Food to feed pigeons was prepared; mixed cereal grain seeds were soaked and macerated in the cassia leaf extract (Senna siamea) in $1.5 \%, 3.0 \%$ and $4.5 \%$ concentrations for $24 \mathrm{~h}$ using both the maceration method and the Soxhlet extraction method; the seeds were dried and added to the experiment.

\section{Experiment Design}

A Completely Randomized Design (CRD) was used for the experiment. There were four treatments and each treatment required three pigeons, with one pigeon per cage. Twenty grams of bird food (the cereal grain seeds) was weighed. The control group was fed with the grain seeds that had not been treated with the cassia leaf extract. The experimental group was fed with the grain seeds that had been treated with the cassia leaf extract in $1.5 \%, 3.0 \%$ and $4.5 \%$ concentrations. The pigeons were fed for $24 \mathrm{~h}$. The weight of the food at the beginning, the amount of leftover food and the weight of pigeon droppings were recorded. Consumption data was analyzed to find differences among the averages of each treatment with a one-way Analysis Of Variance (ANOVA) and to compare the differences between the averages with Duncan's new Multiple Range Test (DMRT). 


\section{Results and Discussion}

Based on the extraction of cassia leaves with the Soxhlet extraction method, the extraction yield was $32 \%$. The results from the comparison of the average of food intake showed that the pigeons had no difference in the average amount of food intake based on the food that had been soaked in the extract using the maceration method, with a statistical significance ( $p>0.05$ ), but the pigeons eating food that had been soaked in the cassia leaf extract with Soxhlet extraction in $1.5 \%, 3.0 \%$ and $4.5 \%$ concentrations (Table 1) had different average amounts of food intake than did the control group, with a statistical significance. However, the comparison of the amount of food that the pigeons ate with that of the control group and the experimental group found that pigeons in the experimental group that were fed with the food that had been soaked in the cassia leaf extract in $1.5 \%, 3.0 \%$ and $4.5 \%$ concentrations showed a lower average of food intake than that of the control group. This probably showed that they were against eating or refused to eat food containing a cassia leaf extract ingredient.

This experiment was performed by using cassia leaf extract and it was assumed that cassia leaves contain anthraquinones. Cassia is native to southern Asia and is the national tree of Thailand. It can be found in every part of Thailand and is locally called "Khun" or "Ratchaphruek". The study on the effects of cassia leaf extracts on the eating behavior of pigeons is based on the hypothesis that anthraquinones in plants enable pigeons to have behaviors that are against cassia leaf extract coated on bird food. This experiment used a solvent of $70 \%$ ethyl alcohol to extract the amount of anthraquinones following (Khoomsab and Khoomsab, 2019) as closely as possible. The experimental results showed that the food that had been soaked in the cassia leaf extract that was processed by the Soxhlet extraction method had the potential to be eaten less than the food that was coated with the extract that had been processed by the maceration method. Based on this hypothesis, there is a concept that when birds eat foods that have an effect on their taste perception or, as in the case of anthraquinones, have an influence on their excretory system that causes them to have an excretory system disorder, the birds will avoid eating those foods repetitively. It is consistent with the study that was conducted by Ahmad et al. (2018), which found with statistical significance that the use of anthraquinone in $0.75 \%$ and $1 \%$ concentrations mixed with corn could cause Eurasian tree sparrows to have a lower rate of food intake than when they ate foods mixed with methyl anthranilate. Considerable research studies have employed such methods for use in agriculture to prevent damage to agricultural products caused by birds. The study of Kandel et al. (2009) used Avipel brand anthraquinone sprayed onto sunflower fields to prevent birds from destroying sunflower seeds. It was found that anthraquinone reduced the destruction from birds and the seed yield was higher than that of the control group. Similar to the finding by Werner et al. (2014) that anthraquinones prevent the destruction of sunflower seeds by black birds in the United States of America, Avery et al. (1998) found that anthraquinones could reduce the destruction of rice by red-winged blackbirds and boat-tailed grackles by using approximately $0.5 \%$ and $1 \%(\mathrm{~g} / \mathrm{g})$ anthraquinone.

One of the pest control uses of anthraquinone is to protect new crops from wild birds, as their attacks can begin right after the seeds were planted.The attacks from seed predator birds can damage seeds whether or not the sapling emerged by being dug out of the soil or was consumed by its coat, hypocotyl and cotyledon (DeLiberto and Werner, 2016). To protect the seeds from seed predator birds, repellents were used without any negative effects on the plant fertilization and anthraquinone was shown to effectively prevent seed predator birds from predating on the protected seeds in the laboratory. In this review, the concentration of anthraquinone that is required to protect each type of seed from a variety of birds was illustrated. For example, $1,700 \mathrm{mg}$ anthraquinone $\mathrm{kg}^{-1}$ applied to sunflower was shown to be $80 \%$ effective against red-winged blackbirds but required up to $12,200 \mathrm{mg}$ anthraquinone $\mathrm{kg}^{-1}$ for common grackles (Werner et al., 2011; 2014). Esther et al. (2013) found the effectiveness of repellency in corn seeds treated with an anthraquinone formula that was extracted from plants and tested on pigeons; the pigeons were offered corn seeds and some were treated with $0.16,1.6$, or $4.8 \mathrm{~mL}$ natural anthraquinone $\mathrm{kg}^{-1}$ while some were treated with 0.5 or $1.0 \mathrm{~mL}$ synthetic anthraquinone $\mathrm{kg}^{-1}$. The result of the experiment showed that corn seeds treated with $1 \mathrm{~mL}$ synthetic anthraquinone $\mathrm{kg}^{-1}$ was preferred by pigeons over untreated corn seeds. As many studies suggested, the mode of action of anthraquinone is to create avoidance in birds after first ingestion due to postingestion pains (Avery et al., 1997; Ahmad et al., 2015; Saleem et al., 2015). However, one study found that anthraquinone did not effectively repel starlings from blueberries or sweet corn (Cummings et al., 2011). Furthermore, validation of the examinations in field settings is still required and is recommended, as the initial experiments were conducted in labs. However, this study recommended concentration anthraquinone extracted from Cassia leaves was $7,500 \mathrm{mg} \mathrm{kg}^{-1}$ (Table 2). 
Kan Khoomsab and Itsara Tangsuwan / American Journal of Agricultural and Biological Sciences 2019, Volume 14: 110.114 DOI: 10.3844/ajabssp.2019.110.114

Table 1: The average of the amount of food intake (grams)

\begin{tabular}{|c|c|c|c|c|}
\hline \multirow[b]{2}{*}{ Methods } & \multicolumn{4}{|c|}{ Treatment concentrations } \\
\hline & Control & $1.5 \%$ & $3 \%$ & $4.5 \%$ \\
\hline Masceration & $18.09 \pm 1.27^{\mathrm{a}}$ & $17.3 \pm 1.15^{\mathrm{a}}$ & $17.2 \pm 0.69^{\mathrm{a}}$ & $18.1 \pm 1.01^{\mathrm{a}}$ \\
\hline Soxhlet extraction & $18.18 \pm 0.32^{\mathrm{A}}$ & $13.0 \pm 1.65^{\mathrm{B}}$ & $14.4 \pm 1.24^{\mathrm{B}}$ & $14.4 \pm 1.35^{\mathrm{B}}$ \\
\hline
\end{tabular}

Means \pm SD in the same row followed by different letters differed significantly $(\mathrm{p}<0.05)$ by DMRT

Table 2: Recommended concentration of anthraquinone $\left(\mathrm{mg} \mathrm{kg}^{-1}\right)$ for avian seed treatment

\begin{tabular}{llll}
\hline Crop & Avian species & Recommended Concentration $\left(\mathrm{mg} \mathrm{AQ} \mathrm{kg}^{-1}\right)$ & Citation \\
\hline Millet & Sturnus vulgaris & 1131 & Poche (1998) \\
Rice & Agelaius phoeniceus & 5000 & Werner et al. $(2009)$ \\
Sunflower & Phasianus colchicus & 15800 & Werner et al. (2011) \\
Wheat & Passer domesticus & 10000 & Ahmad et al. $(2015)$ \\
Corn & Corvus splendens & 10000 & Saleem et al. (2015) \\
Mixed seed & Columba livia & 7500 & This study \\
\hline
\end{tabular}

Generally, two types of repellents have been classified by methods of functionality (Avery, 2002). Primary repellents can cause irritation that could be painful with exposure, including contact with birds, so birds reflectively avoid primary repellants without the need of other additional methods. While many repellents are poisonous, birds exposed to only a small amount of toxicity that causes them no harm will avoid food treated by repellents, as they tend to avoid ingesting such food due to the aversive compound of repellents. One of the compounds that is a primary component of repellent is methyl anthranilate, which is the same compound that was used to stop birds from feeding. Another compound, while not immediately aversive, could cause sickness or discomfort on some occasions after ingestion. The strength of the effect from these compounds depends on food avoidance behavior in avian, as they identify adversity from past experience and even some sensory attributes of the food, such as color, taste, or odor (Avery, 2002). The secondary repellent compound is anthraquinone, which a causes postingestion pains, even to the extent of vomiting. However, vomiting after the digestion of anthraquinone did not occur frequently and the birds that ingested it would normally stay put until the pain went away. In this way, birds remember which foods caused adversity and tend to avoid such foods later on (Avery, 2002). Anthraquinones are famous for their laxative property, for which one of the laxative effects is caused by alteration in colonic absorption and secretion, which results in fluid accumulation and, consequently, diarrhea (Sakulpanich et al., 2012).

\section{Conclusion}

Cassia is a secondary repellent compound. Cassia was shown to be effective, as food consumption of treated food was lower than that of the control. Ingesting cassia irritates the digestive tract of birds and has an adverse effect on their bodies. Species of cassia are rich sources of anthraquinones. Therefore, cassia is one of the bird repellents that may be sourced from various areas of
Thailand. In the next experiment, the concentration of extracts should be increased and other plants containing anthraquinone, such as golden shower, noni, or Sichuan pepper, should be explored.

\section{Acknowledgment}

This research was funded by the Research and Development Institute, Phetchabun Rajabhat University, from their research budget for the year 2018. The researchers would like to thank all supporters.

\section{Authors Contributions}

Kan Khoomsab: Designed experiment, analyzed data and statistics, writing manuscript, publication process.

Itsara Tangsuwan: Prepared plant sample and instruments. Prepared animals, treated animals and collected data for experiment.

\section{Ethics}

This experiment was carried out under Animals for Scientific Purposes Act B.E.2558 (2015), License for using and producing animals for scientific purposes number U1-020037-2558, Dr. Kan Khoomsab.

\section{References}

Ahmad, S., F. Jabeen, H.A. Khan, K. Samiullah and S. Yaqub et al., 2015. Effectivness of anthraquinone and methylanthranilate against house sparrow (Passer domesticus) from wheat seeds and seedlings in caged conditions in Pakistan. J. Biodivers. Environ. Sci., 6: 326-334.

Ahmad, S., Z. Saleem, F. Jabeen, B., Hussain and T. Sultana et al., 2018. Potential of natural repellents methylanthranilate and anthraquinone applied on maize seeds and seedlings against house sparrow (Passer domesticus) in captivity. Braz. J. Biol., 78: 667-672. DOI: 10.1590/1519-6984.171686 
Avery, M.L., 1992. Evaluation of methyl anthranilate as a bird repellent in fruit crops. Proceedings of the 15th Vertebrate Pest Conference, pp: 130-133.

Avery, M.L., J.S. Humphrey and D.G. Decker, 1997. Feeding deterrence of anthraquinone, anthracene and anthrone to rice-eating birds. J. Wild. Manage., 61: 1359-1365. DOI: 10.2307/3802138

Avery, M.L., J.S. Humphrey, T.M. Primus, D.G. Decker and A.P. McGrane, 1998. Anthraquinone protects rice seed from birds. Crop Protect., 17: 225-230. DOI: 10.1016/S0261-2194(98)00002-7

Avery, M.L., 2002. Avian repellent. USDA National Wildlife Research Center - Staff Publications.

Bishop, J.B., H. Mckay, D. Parrott and J. Allan, 2003. Review of international research literature regarding the effectiveness of auditory bird scaring techniques and potential alternatives.

Bussmann, R.W., L. Hennig, A. Giannis, J. Ortwein and T.M. Kutchan et al., 2013. Anthraquinone content in noni (Morinda citrifolia L.). Evidence-Based Complementary Alternative Med. DOI: $10.1155 / 2013 / 208378$

Clapperton, B.K., R.E. Porter, T.D. Day, J.R. Waas and L.R. Matthews, 2012. Designer repellents: Combining olfactory, visual or taste cues with a secondary repellent to deter free-ranging house sparrows from feeding. Pest. Manage. Sci., 68: 870-877. DOI: $10.1002 / p s .3244$

Cummings, J.L., R.W. Byrd, W.R. Eddleman, R.M. Engeman and S.K. Tupper, 2011. Effectiveness of AV-1011 to reduce damage to drill-planted rice from blackbirds. J. Wildl. Manage., 75: 353-356. DOI: 10.1002/jwmg.65

Dave, H. and L. Led, 2012. A review on anthraquinone from cassia species and their application. Indian $\mathbf{J}$. Natural Product Resources, 3: 291-319.

Day, T.D., B.K. Clapperton, R.ER. Porter, J.R. Waas and LR. Matthews, 2012. Responses of free-ranging house sparrows to feed containing primary and secondary repellents. New. Zeal. J. Crop. Hort., 40: 127-138. DOI: 10.1080/01140671.2011.630738

DeLiberto, S.T. and S.J. Werner, 2016. Review of anthraquinone application for pest management and agricultural crip protection. Pest. Manage. Sci., 73: 1813-1825. DOI: $10.1002 /$ ps.4330

Esther, A., R. Tilcher and J. Jacob, 2013. Assessing the effects of three potential chemical repellents to prevent bird damage to corn seeds and seedlings. Pest. Manage. Sci., 69: 425-430. DOI: 10.1002/ps.3288

Kandel, H., B. Johnson, C. Deplazes, G. Linz and M. Santer, 2009. Sunflower treated with avipel (Anthraquinone) bird repellent. USDA National Wildlife Research Center - Staff Publications.

Khoomsab, R. and K. Khoomsab, 2019. Extraction and determination of anthraquinone from herbal plant as bird repellent. Sci. Technol. Asia, 24: 14-20.
Linz, G.M. and H.J. Homan, 2012. Preliminary evaluation of 9,10 anthraquinone bird repellent for managing blackbird damage to ripening sunflower. Proceedings of the 34th National Sunflower Association Sunflower Research Workshop, pp: 1-5.

Poche, R.M., 1998. Development of a new bird repellent, Flight Control. Proceedings of the Vertebrate Pest Conference, (VPC' 98), pp: 338-344.

Saleem, Z., S. Ahmad, F. Jabeen, H.A. Khan and S. Yaqub et al., 2015. Efficacy of methylanthranilate and anthraquinone against house crow (Corvus splendens) from maize seeds and seedlings in aviary conditions in Pakistan. J. Biodivers. Environ. Sci., 6: 435-444.

Sakulpanich, A. and W. Gritsanapan, 2009. Laxative anthraquinone content in fresh and cooked Senna siamea leaves. Southeast Asian. J. Trop. Med. Public Health, 40: 835-839.

Sakulpanich, A., S. Chewchinda, P. Sithisarn and W. Gritsanapan, 2012. Standardization and toxicity evaluation of Cassia fistula pod pulp extract for alternative source of herbal laxative drug. Phcog. J., 4: 6-12. DOI: $10.5530 / p j .2012 .28 .2$

Shami, A.M., 2015. Isolation and identification of anthraquinones extracted from Morinda Citrifolia L. (Rubiaceae). Ann. Chromatogr. Sep. Tech., 1: 1-3. DOI: $10.36876 /$ acst. 1012

Umeda, K. and L. Sullivan, 2001. Evaluation of methyl anthranilate for use as a bird repellent in selected crops. Vegetable Report of University of Arizona College of Agriculture.

Vantassel, S.M., 2010. Urban pets birds: Controlling damage. Wildlife Management Wildlife Damage Control.

Werner, S.J., J.C. Carlson, S.K. Tupper, M.M. Santer and G.M. Linz, 2009. Threshold concentrations of an anthraquinone-based repellent for Canada geese, red-winged blackbirds and ring-necked pheasants. Applied Anim. Behav. Sci., 121: 190-196.

DOI: 10.1016/j.applanim.2009.09.016

Werner, S.J., G.M. Linz, J.C. Carlson, S.E. Pettit and S.K. Tupper et al., 2011. Anthraquinone-based bird repellent for sunflower crops. Applied Anim. Behav. Sci., 129: 162-169.

DOI: $10.1016 /$ j.applanim.2010.11.010

Werner, S.J., S.K. Tupper, S.E. Pettit, J.W. Ellis and J.C. Carlson et al., 2014. Application strategies for an anthraquinone-based repellent to protect oilseed sunflower crops from pest blackbirds. Crop Prot., 59: 63-70. DOI: 10.1016/j.cropro.2014.01.016 